\title{
QUANTIFICATION OF TRANSPULMONARY ECHOCONTRAST EFFECTS
}

\author{
N. De Jong, F. J. ten Cate, W. B. Vletter and J. R. T. C. Roelandt \\ Department of Cardiology and Experimental Echocardiography, Thoraxcenter, University Hospital Dijkzigt \\ and Erasmus University Rotterdam, The Netherlands
}

(Received 1 October 1992; in final form 4 December 1992)

\begin{abstract}
Videodensity of left heart and right heart were studied after intravenous injection of increasing dosages of 0.01-0.02 and $0.04 \mathrm{~mL} / \mathrm{kg}$ bodyweight of Albunex ${ }^{\mathbb{B}}$ in 10 healthy volunteers. The increase in videodensity in the left ventricle was always lower than in the right ventricle. Possible explanations are diffusion of gases caused by ambient pressures changes and change in microspheres distribution due to the sieving effect of the lung capillary bed. These phenomena were studied in vitro and were consistent with clinical observations. These limitations restrict a quantitative assessment of left heart echocontrast after intravenous injection.
\end{abstract}

Key Words: Perfusion, Ultrasound, Videodensity, Backscatter, Albunex ${ }^{\circledast}$.

\section{INTRODUCTION}

Contrast echocardiography has been evolving since 1968 when Gramiak and Shah observed a contrast effect following indocyanine dye injection on $\mathrm{M}$ mode echocardiograms. Since that time, the clinical application of contrast echocardiography has been largely replaced by color Doppler flow imaging. More recently, contrast echocardiography gained renewed interest in experimental studies indicating its potential to assess myocardial perfusion. Using intracoronary or intraaortic injections, contrast agents have been used to identify myocardial perfusion defects (Armstrong et al. 1982) and areas at risk (Kaul et al. 1984), and to indicate coronary blood flow (Tei et al. 1984; Ten Cate et al. 1984a) or flow reserve (Cheirif et al. 1988; Keller et al. 1988a). However, in order to accurately measure perfusion, a contrast agent must satisfy several criteria. It should be inert, that is, without systemic hemodynamic effects and should not alter coronary blood flow (Keller et al. 1988b). The microspheres which provide backscatter for echocardiographic imaging should not be larger than red blood cells, have identical velocity flow profiles and physiologic transit times without impeding flow. The microspheres must persist long enough to perfuse the tissue to be imaged, and provide adequate ultrasound backscatter to be detected with available equipment.

Address correspondence to: N. de Jong, EE2302, Erasmus University Rotterdam, P.O. Box 1738, 3000 DR Rotterdam, The Netherlands.
For quantification, the ultrasound properties of the agent have to be known together with the concentration and size distribution in the area of interest. Agents which have been used in the past have failed to meet one or more of these criteria. Many are hyperosmolar and therefore alter coronary blood flow and/or systemic blood pressure (Hajduczki et al. 1987; Kloster et al. 1972; Kondo et al. 1984), while others alter left ventricular contractility. Hand-agitated solutions and hydrogen peroxide contain relatively large microspheres providing good backscatter, but impeding capillary flow and have prolonged transit times (Feinstein et al. 1984; Ten Cate et al. 1984b). Also, microspheres used in early studies were neither small nor stable enough to pass through the pulmonary circulation in sufficient quantities to opacify the left ventricle following an intravenous injection (Meltzer et al. 1980).

Experimental studies with sonicated albumin microspheres have shown that these are sufficiently small and stable, with satisfactory longevity and capable of passing through the pulmonary circulation in experimental animals and that they do not alter hemodynamics, coronary blood flow, or left ventricular contractility (Keller et al. 1987). Furthermore, sonicated albumin microspheres can be generated in high concentrations, thus providing an intense backscatter despite their small size. Sonicated albumin therefore appears to fulfill all the criteria set forth for an "ideal" myocardial contrast echo agent.

Recently, clinical experience using intravenous Albunex ${ }^{\circledast}$, a sonicated albumin solution containing 
stable microspheres of known sizes and concentration, has been reported. The agent is safe and causes left heart opacification after intravenous injection (Feinstein et al. 1990). We studied the in vitro behavior of Albunex in order to explain the observed contrast effects in the right and left ventricle after intravenous injection of increasing dosages of Albunex ${ }^{\circledast}$ in humans.

\section{METHODS AND PATIENTS}

The studies were performed in 10 healthy male volunteers, age 20-25 years after giving written informed consent. All underwent a complete history and physical examination, electrocardiogram, and laboratory evaluation including glucose, serum electrolytes, urea, creatinine, calcium, phosphate, uric acid, cholesterol, liver profile, complete blood count, thrombin time, and urinalysis. All subjects were required to be within $10 \%$ of their ideal body weight, with blood pressure between 100-140/70-90 mm Hg, heart rate between $50-90$ beats/min, temperature less than 37.1 centigrade, electrocardiogram normal, and laboratory results without significant abnormalities. Exclusion criteria included previous neurologic, cardiac or lung disease, known right to left heart shunts, blood product allergies, drug or alcohol dependence, or women of child-bearing potential. No echocardiographic abnormalities were noted. These volunteers can be defined as normal in so far as this can be established by complete medical examination. The protocol was approved by the Medical Ethics Committee of the hospital. The safety aspects have been reported recently (Feinstein et al. 1990).

\section{Two-dimensional (2D) echocardiographic examina- tion}

The volunteers were examined in the left lateral decubitus position using a Toshiba SSH/160A apparatus with a $3.75 \mathrm{MHz}$ phased array transducer. Since they were all healthy young volunteers, they were able to breathe as superficially as possible. This was done to keep the 2D echo image as stable as possible during the injection of Albunex ${ }^{\circledast}$ and to minimize the effects of venous return on the echocontrast images. Apical four-chamber views were obtained, and gain settings and density were optimized at the beginning of the examination. These settings were not changed during the examination. Images were recorded on VHS videotape.

\section{Albunex administration protocol}

Subjects had a 20-gauge intravenous catheter placed in a large forearm vein and maintenance infusion of normal saline was initiated. The contrast agent used (Albunex ${ }^{\circledR}$, Molecular Biosystems, San Diego, CA, USA) is a stable, prepared albumin-based agent consisting of microspheres with a mean diameter between 3-5 $\mu \mathrm{m}$ in size. Two solutions of different microsphere concentration were administered, $4.7 \times 10^{8}$ microspheres $/ \mathrm{mL}$ (low concentration) and $8.3 \times 10^{8}$ microspheres/mL (high concentration). Three different dosages were used: $0.01,0.02$ and $0.04 \mathrm{~mL}$ per $\mathrm{kg}$ body weight. Prior to the first Albunex ${ }^{\circledR}$ injection, subjects received a $1 \mathrm{~mL}$ dose of $5 \%$ human albumin as control. The complete dosage regimen is given in Table 1. Injections were administered through a three-way stopcock connected to the intravenous catheter, and following each injection, the saline was allowed to run wide open for $30 \mathrm{~s}$ to flush the injection. After injections, the heart rate, blood pressure, respiratory rate and electrocardiogram (via the single lead electrocardiogram displayed on the echo apparatus) were recorded and a neurologic evaluation was made.

Two-dimensional echo imaging was performed just prior to each injection and continued for $3 \mathrm{~min}$ following each injection or until contrast was no longer visible. A final four-chamber image was recorded following the last injection. An example of a video recording just before injection and its peak density after the injection is shown in Fig. 1.

\section{Videodensitometry}

The video-recorded images were digitized via an IBM AT computer, connected to a high resolution frame grabber which allows acquisition of 52 frames. Image resolution was $512 \times 512$ pixels. The video gray-scale values were expressed in 256 ( 8 bit resolution) levels, where the value 0 means black (no echo) and 256 white (maximum echo). The video gray-scale value is called density throughout the paper and is expressed in arbitrary units.

For videodensity measurements, five regions of interest for each of the 52 acquired images are used. Position and orientation of each region can be ad-

Table 1. Dosage regimen for the 10 volunteers participating in the study. Low concentration $=4.7 \times 10^{8}$, high concentration $=8.3 \times 10^{8}$ microspheres $/ \mathrm{mL}$.

\begin{tabular}{|c|c|c|c|}
\hline $\begin{array}{c}\text { Injection } \\
\text { no. }\end{array}$ & Material & Dosage & Concentration \\
\hline 0 & Human serum albumin & $1 \mathrm{~mL}$ & $5 \%$ \\
\hline 1 & Albunex & $.01 \mathrm{~mL} / \mathrm{kg}$ & low \\
\hline 2 & Albunex & $.01 \mathrm{~mL} / \mathrm{kg}$ & high \\
\hline 3 & Albunex & $.02 \mathrm{~mL} / \mathrm{kg}$ & low \\
\hline 4 & Albunex & $.02 \mathrm{~mL} / \mathrm{kg}$ & high \\
\hline 5 & Albunex ${ }^{\otimes}$ & $.04 \mathrm{~mL} / \mathrm{kg}$ & low \\
\hline 6 & Albunex & $.04 \mathrm{~mL} / \mathrm{kg}$ & high \\
\hline
\end{tabular}



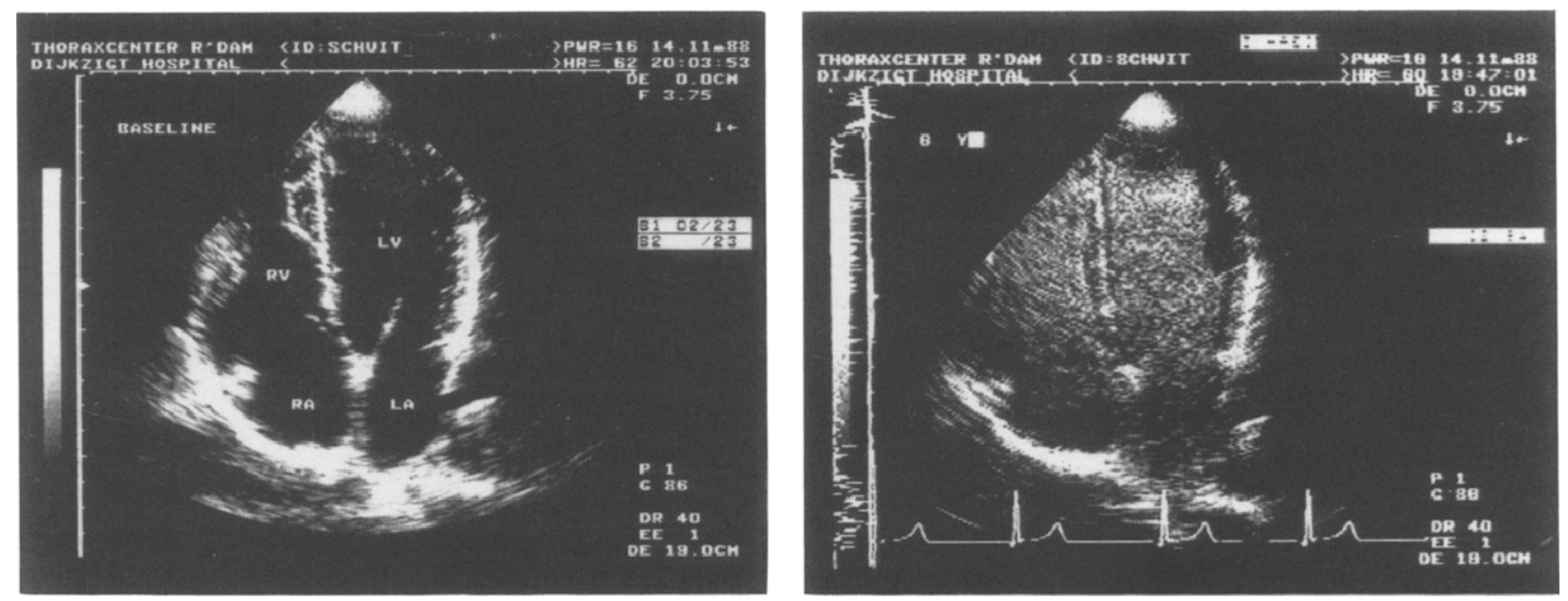

Fig. 1. Representative example of a 2D-echocardiographic four-chamber view in one of the subjects. Left panel shows an echo image before intravenous injection of Albunex ${ }^{\circledast}$, right panel, $40 \mathrm{~s}$ after injection. Abbreviations: $\mathrm{LA}=$ left atrium; $\mathrm{LV}=$ left ventricle; $\mathrm{RA}=$ right atrium; $\mathrm{RV}=$ right ventricle.

justed independently in all images. It is also possible to change the preset regions of interest in particular images as all information is stored on disk and is always available for reprocessing. Measurements are carried out automatically once all regions are defined. Analysis includes measurements of the mean density and deviation in each region as well the corresponding time density curve. All parameters of this curve can be calculated, including the maximum density, density increase and decrease, and area under the curve.

The regions of interest were placed in the right ventricular cavity (1), the inflow part of the left ventricular cavity (2), the apex of the left ventricular cavity (3), the middle of the interventricular septal myocardium (4) and the myocardium of the lateral wall of the left ventricle (5) (see Fig. 2).

When contrast was visually detected, five end-diastolic frames prior to contrast appearance were taken as start frame. Fifty-two successive end-diastolic frames were then grabbed into the computer for analysis of the time course of contrast appearance and disappearance.

We chose end-diastolic frames because these images were most stable and most clearly showed the effects of the contrast agent. The computer stored all the measured intensities and constructed a time density curve of echo contrast appearance and disappearance for the different regions. For each region the mean density was also determined.

The final time-density curve was constructed by subtracting the baseline density and by performing a low-pass filtering to smooth the curve. Furthermore, two beats were selected for a frame-by-frame video- density analysis in both the left as well as the right ventricle in order to register cyclic variations. For the right ventricle, the beats were taken after sufficiently long time after injection when attenuation was minimal; for the left ventricle, around the time at which peak density occurred.

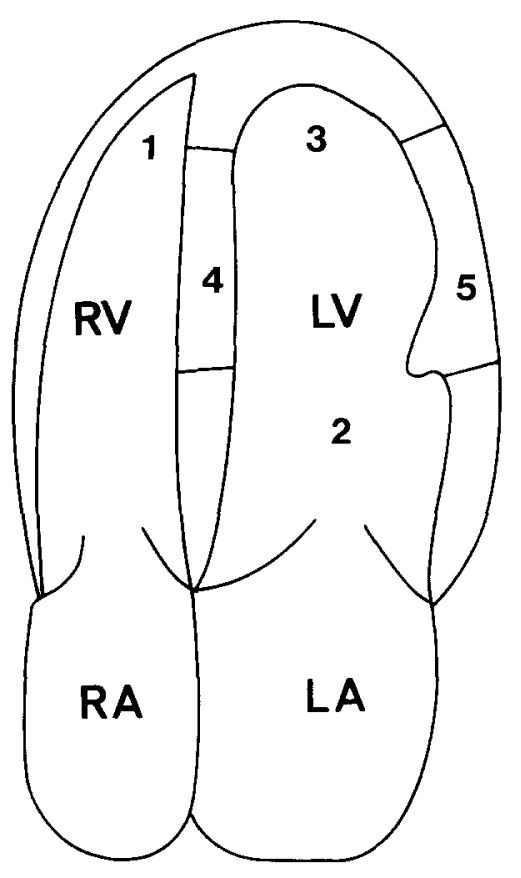

Fig. 2. Schematic illustrations of the five regions of interest for determinations of the videodensities. (1) right ventricular cavity, (2) the inflow part of the left ventricular cavity, (3) the apex of the left ventricular cavity, (4) the middle of the interventricular septal myocardium, and (5) the myocardium of the lateral wall of the left ventricle. 


\section{In vitro studies}

Microscopic investigations were performed on Albunex (concentration of the batch used: 3.72 microspheres $/ \mathrm{mL}$ ). Albunex ${ }^{\circledR}$ was diluted 1:200 in 5\% human serum albumin and was put in a cavity which could be placed under a microscope. The human serum albumin was air saturated at atmospheric pressure. The pressure inside the cavity could be controlled between 0 and $200 \mathrm{~mm} \mathrm{Hg}$. A camera was mounted on the microscope to record the images. After placing the cavity with diluted Albunex ${ }^{\circledR}$ under the microscope, first recordings were made under ambient pressure, in order to check that the initial conditions of the human serum albumin did not influence the microspheres. After $1 \mathrm{~min}$ a static overpressure of $160 \mathrm{~mm} \mathrm{Hg}$ was applied, and the microspheres' numbers and shapes were visually studied.

To calculate the influence on the backscatter power of Albunex ${ }^{\circledast}$ caused by the sieving actions of the lungs, the size distribution of the pulmonary capillaries as described by Hogg (1987) is used. Before lung passage a typical size distribution of Albunex ${ }^{\circledR}$ is assumed; after lung passage it is assumed that the larger microspheres have been sieved away according to the size distribution of the pulmonary capillaries. The calculated backscatter power is based on the expected size distribution and the theoretical model of an $\mathrm{Al}-$ bunex ${ }^{\circledR}$ microsphere. This model theoretically describes the attenuation and scatter properties of a microsphere (De Jong et al. 1992; De Jong and Hoff 1993).

\section{RESULTS}

\section{Safety}

In this study two different concentrations of $\mathrm{Al}-$ bunex $^{\circledR}$ were used. There were no laboratory, electrophysiologic, general physical or neurologic abnormalities detected either before, immediately after or three days after the study related to the injection of $\mathrm{Al}-$ bunex $^{\circledR}$ or human serum albumin (Feinstein et al. 1990).

\section{Videodensitometry}

The control injection of 5\% human serum albumin did not show an enhancement of the videodensity in any region. The contrast effect in all patients as measured in the left and right ventricle is shown in Fig. 3. In this figure the density increases for a low dose (injection 2) and for a high dose (injection 6) are given. It shows that the contrast effect in the right ventricle was always higher than in the left ventricle. Furthermore, Albunex ${ }^{\circledR}$ appears in the left ventricle of all subjects at

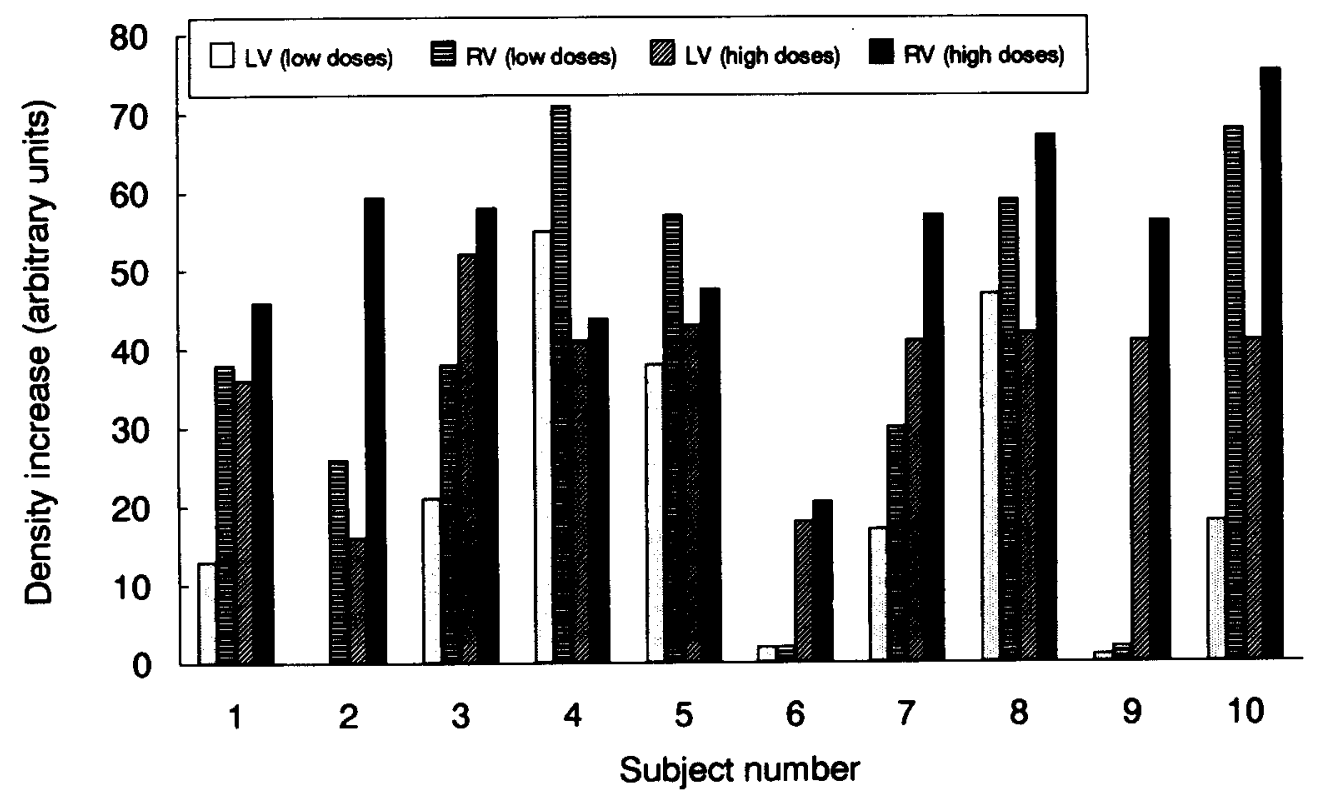

Fig. 3. The measured density increase in the left and right ventricle after an intravenous injection of Albunex ${ }^{\otimes}$ for the 10 subjects studied. $\square=$ Density increase in the left ventricle after intravenous injection of $0.01 \mathrm{~mL} \mathrm{Albunex} \%$ $\mathrm{kg}$ and for the high concentration of Albunex $\left(8.3 * 10^{8}\right.$ microspheres $\left./ \mathrm{mL}\right)$. 圈 $=$ Density increase in the right ventricle after intravenous injection of $0.01 \mathrm{~mL}$ Albunex ${ }^{\otimes} / \mathrm{kg}$ and for the high concentration of Albunex ${ }^{\otimes}\left(8.3 * 10^{8}\right.$ microspheres $/ \mathrm{mL}$ ). 圆 = Density increase in the left ventricle after intravenous injection of $0.04 \mathrm{~mL} \mathrm{Albunex}{ }^{\otimes} / \mathrm{kg}$ and for the high concentration of Albunex $\left(8.3 * 10^{8}\right.$ microspheres $\left./ \mathrm{mL}\right)$. $\mathbf{\square}=$ Density increase in the right ventricle after intravenous injection of $0.04 \mathrm{~mL}$ Albunex $\otimes / \mathrm{kg}$ and for high concentration of Albunex ${ }^{\circledast}\left(8.3 * 10^{8}\right.$ microspheres/mL). 


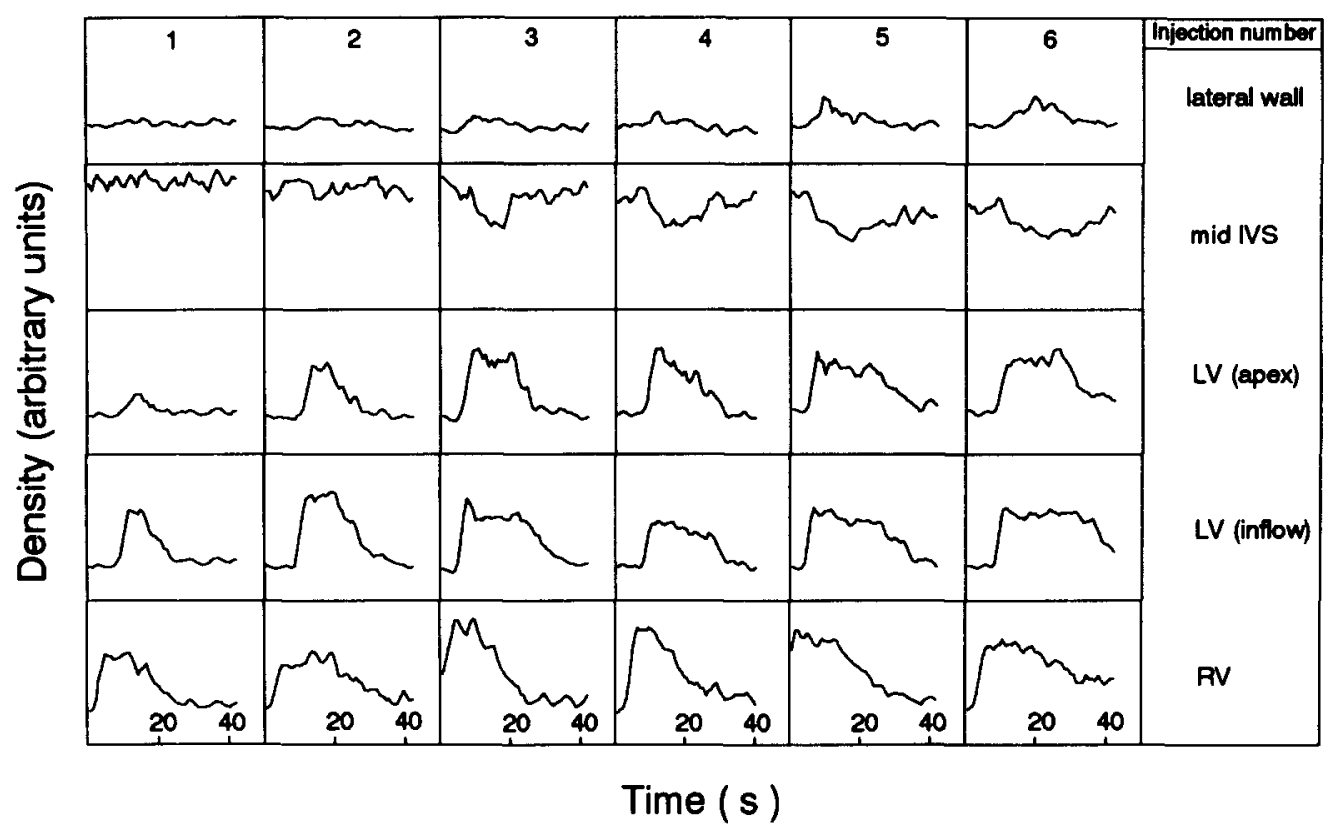

Fig. 4. Example of measured videodensity curves of one of the subjects for the injections provided (1-6) at the regions of interest studied. The injection number is denoted horizontally, the region of interest, vertically.

the highest dose, but a positive indication is also apparent at lower dosages. For example at the lowest dosages with a high concentration of Albunex ${ }^{\circledR}$ (injection 2), 8 out of 10 subjects have an increased density in the left ventricle, although nothing could be detected for two subjects (nos. 2,9). The negative result in patient no. 9 can be explained by the administration procedure during which a mechanical obstruction of the venous drainage from the left arm occurred.

An example of contrast effects as observed in one patient is shown in Fig. 4. The measured time-density curve is displayed in each box and corresponds to $45 \mathrm{~s}$ of contrast effect. The different injections are ordered by column while the different regions are ordered sequentially by row. A variety of parameters can be calculated from these recordings, such as time of arrival of contrast area under the curve, peak density, etc.

The density curves from the midinterventricular septum are difficult to interpret because of "shadowing" by the contrast effect from the left ventricle apex.
A small increase in density at the highest dosage was seen in the lateral wall of two subjects, one of which is shown in Fig. 4.

The mean density increases together with their standard deviations for all objects are given in Table 2 . The different regions are shown vertically and the injection numbers, horizontally. There is an increase in density for regions 1, 2, 3 for almost all injections. For regions 4 and 5 there is no significant increase of the measured density. The average density in the right ventricle is higher than the left ventricle which is already shown in Fig. 3.

There was generally a very high attenuation caused by the contrast in the right ventricle and this was most apparent at the highest dosages. As a result, only a very small band along the edge of the right ventricle could be seen interfering with the visualization of more distant structures. Attenuation in the right ventricle as high as $60 \mathrm{~dB} / \mathrm{cm}$ was noticed, while in the left ventricle it is generally much less, 1 to $3 \mathrm{~dB} / \mathrm{cm}$.

Table 2. Mean density increase and standard deviation for the 5 regions of interest and 6 injections.

\begin{tabular}{crrrrrr}
\hline & \multicolumn{7}{c}{ Injection number } \\
\cline { 2 - 7 } Region & \multicolumn{1}{c}{1} & \multicolumn{7}{c}{3} & 4 & 5 & 6 \\
\hline & $29 \pm 17$ & $35 \pm 22$ & $46 \pm 23$ & $47 \pm 17$ & $47 \pm 18$ & $53 \pm 15$ \\
2 & $13 \pm 14$ & $18 \pm 18$ & $24 \pm 18$ & $24 \pm 14$ & $25 \pm 16$ & $33 \pm 16$ \\
3 & $7 \pm 5$ & $16 \pm 14$ & $28 \pm 22$ & $25 \pm 16$ & $31 \pm 19$ & $44 \pm 16$ \\
4 & $13 \pm 10$ & $8 \pm 8$ & $13 \pm 5$ & $12 \pm 6$ & $13 \pm 7$ & $14 \pm 8$ \\
5 & $5 \pm 4$ & $5 \pm 3$ & $7 \pm 6$ & $10 \pm 13$ & $8 \pm 5$ & $11 \pm 8$ \\
\hline
\end{tabular}




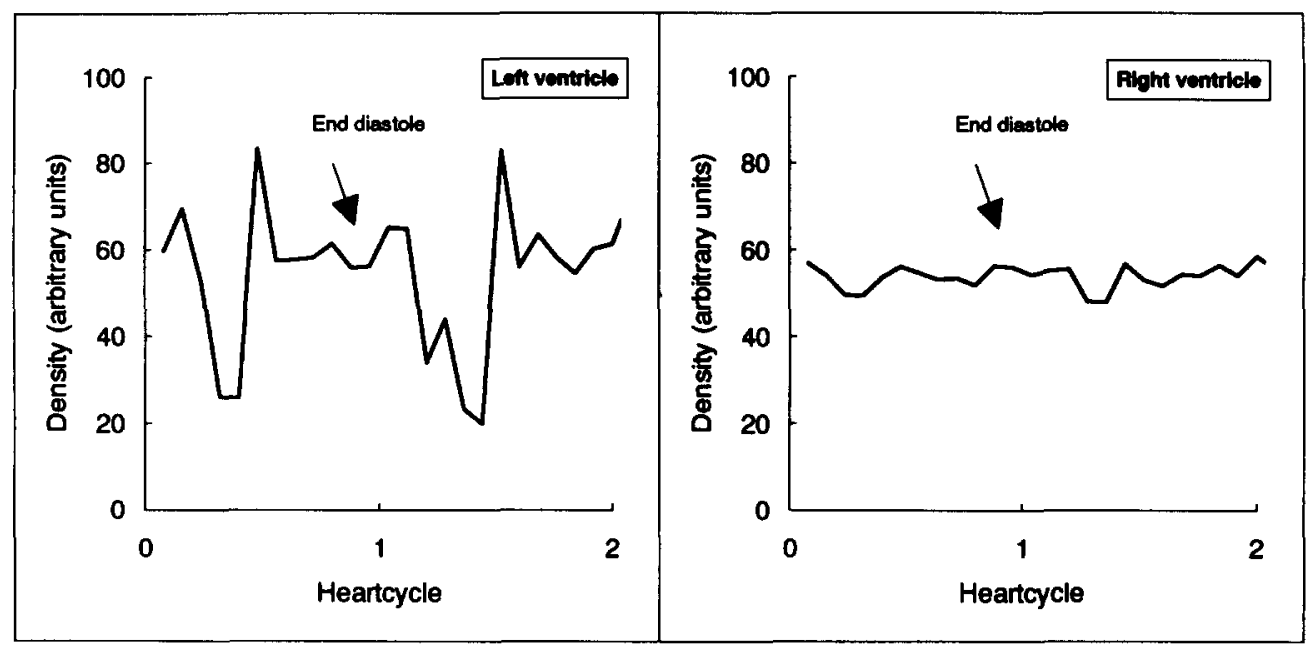

Fig. 5. Measured videodensity of one of the subjects represented over two entire heart cycles. The left panel shows the measurement in the left ventricle $20 \mathrm{~s}$ after injection; the right panel shows the measurement in the right ventricle $40 \mathrm{~s}$ after the same injection.

The difference in density increase ranges between 3 and 45 "gray-scale" values. This suggests loss of microspheres during transit between the right and the left ventricles. Furthermore, there is an unexpectedly large variation of the increase in density. This apparent variation among normal subjects might have sev- eral causes including: 1) different Albunex ${ }^{\circledast}$ characteristics, 2) different physical situation (i.e., subject dependency), and 3) procedure dependency. The fact that a smaller variability in density values is observed in the left ventricle suggests that the microspheres appearing in the left ventricle are less sensitive to these

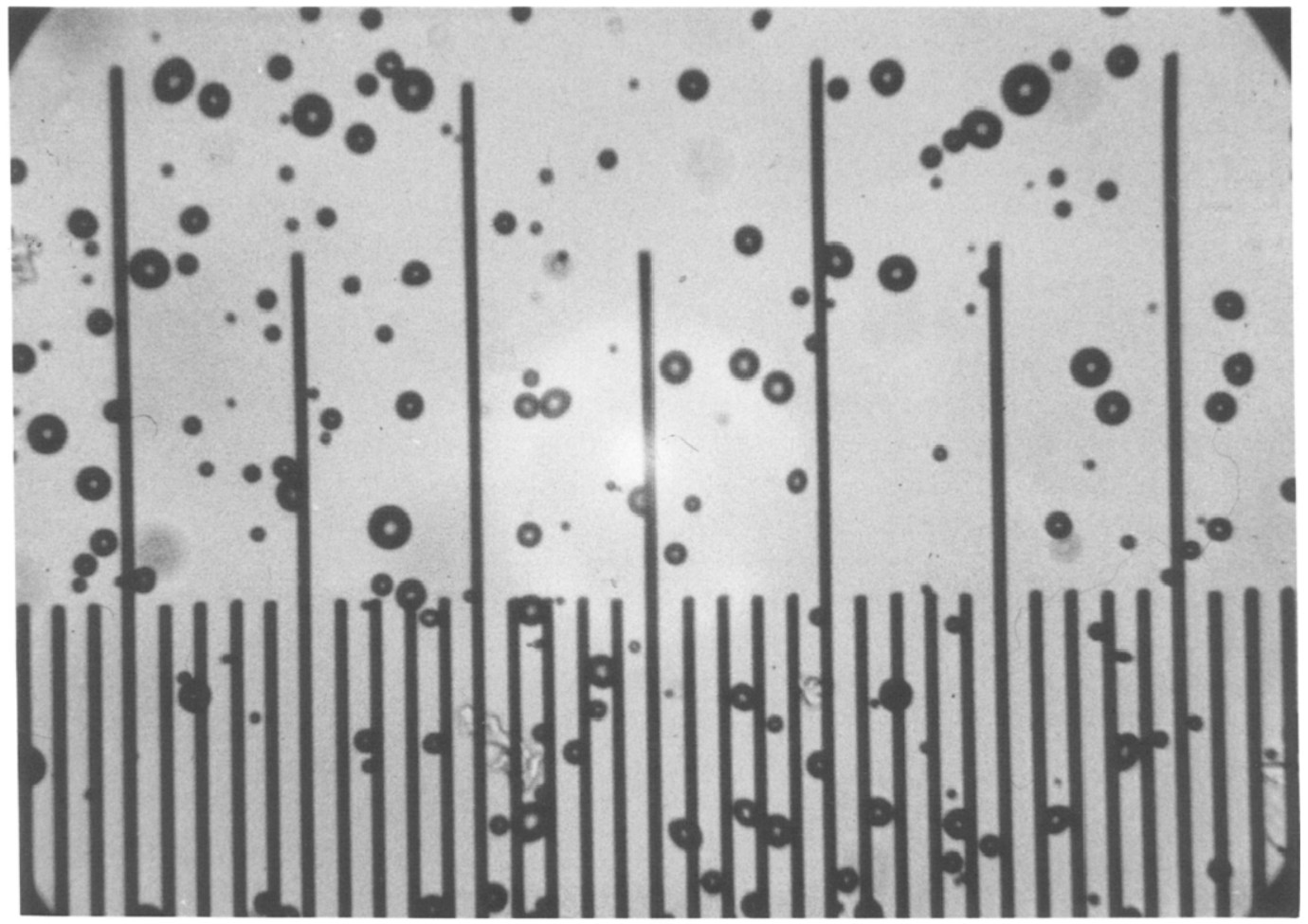

(a)

Fig. 6. Microscopic view of diluted Albunex: (a) just before overpressure, (b) $1 \mathrm{~s}$ after applying an overpressure of $160 \mathrm{mmHg}$, and (c) $5 \mathrm{~s}$ after applying an overpressure of $160 \mathrm{mmHg}$. 


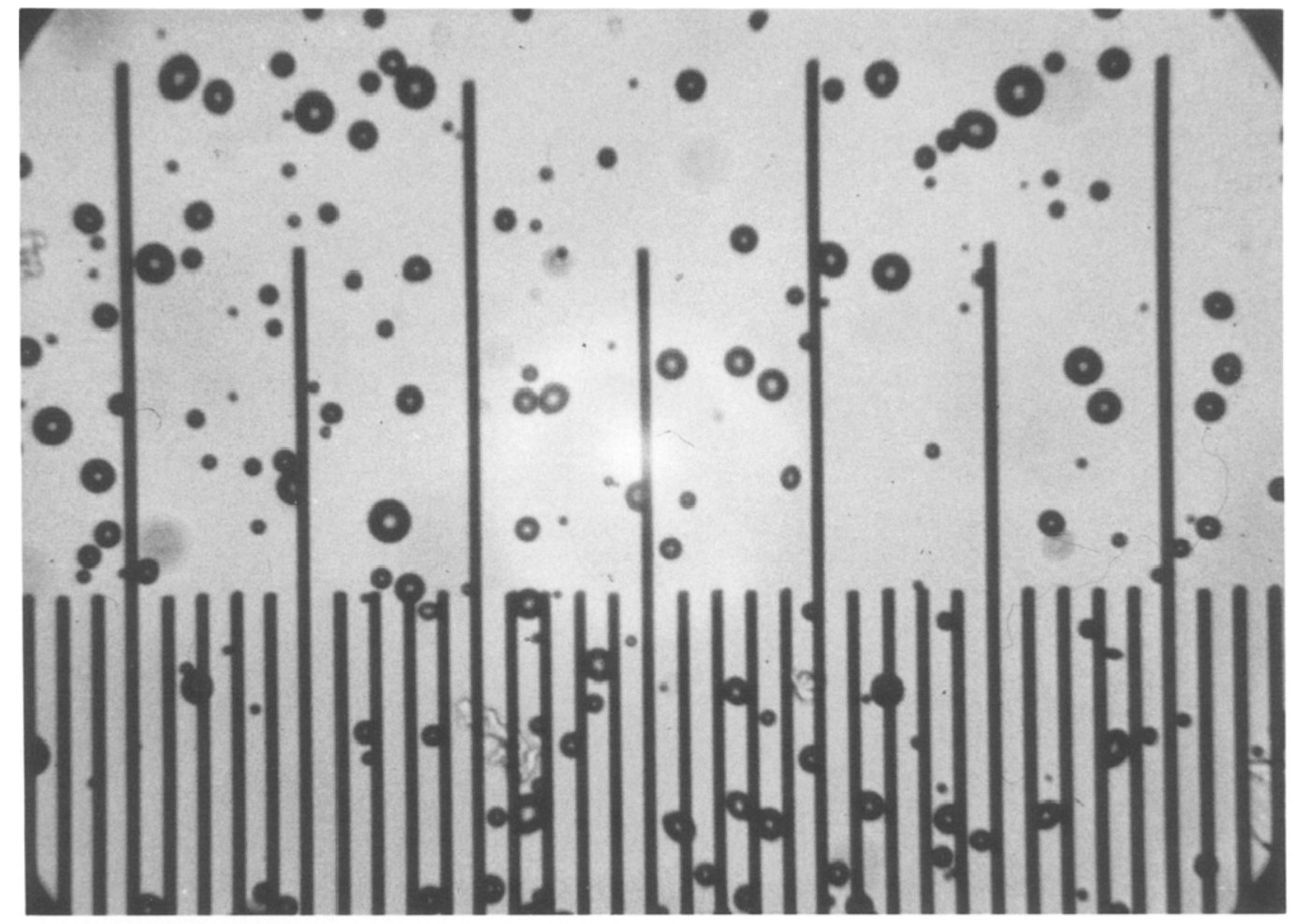

(b)

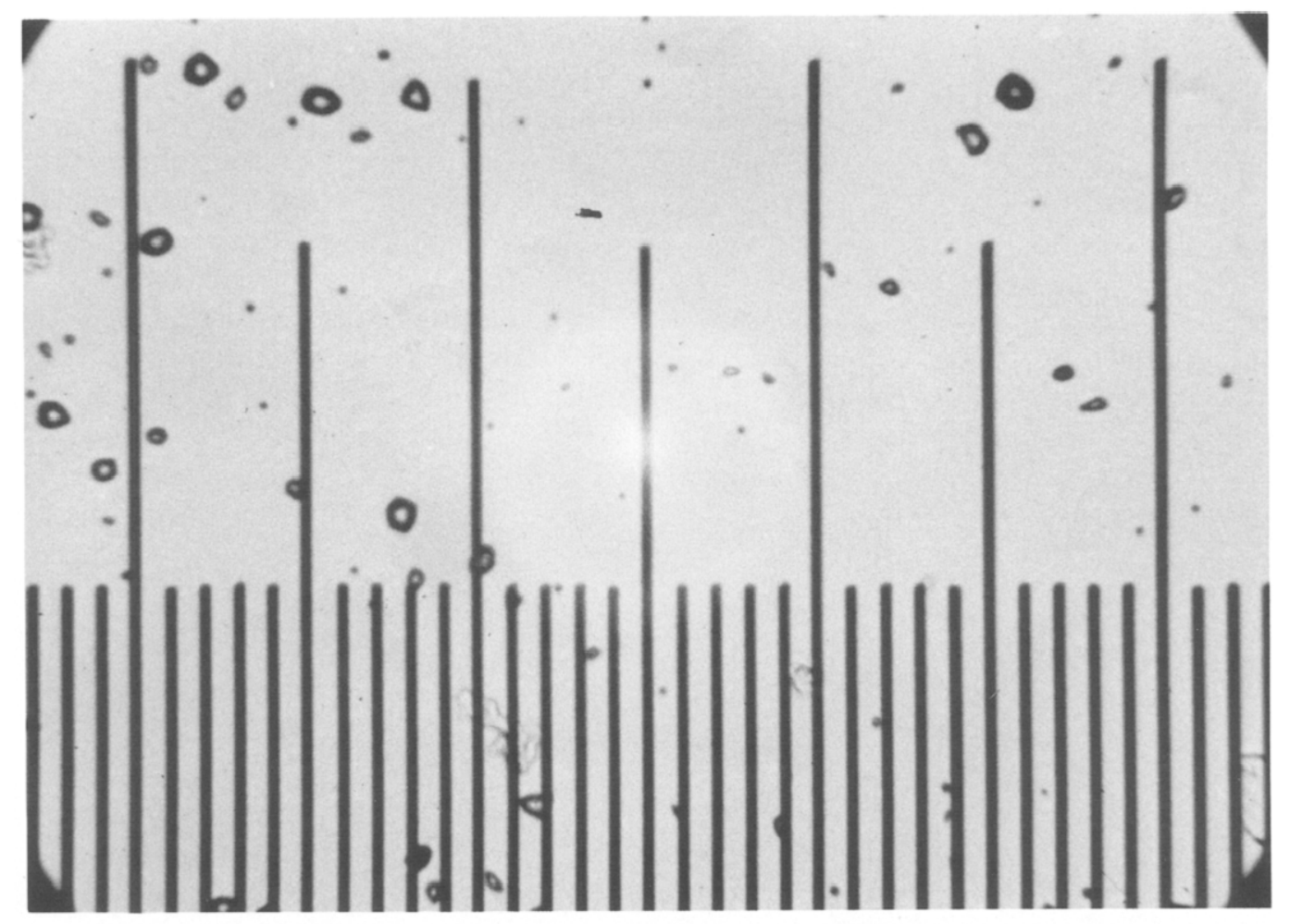

(c)

Fig. 6. Continued. 
causative factor(s). This can be caused by larger microspheres, which would only appear in the right ventricle, and these larger microspheres are responsible for the variations seen. Since Albunex ${ }^{\circledR}$ needs careful handling, large variations through handling of the product might occur.

The measured density variation in the left ventricle and right ventricle during two heart cycles of one patient is shown in Fig. 5. The sampling rate permitted 12 measurements per cardiac cycle. The right ventricle density variation is about five units and is lowest at end-systole. This may indicate that total backscatter is pressure dependent. The same pattern is apparent for the left ventricle density measurements (range 60 units), although the variation is much larger and consistent with the higher pressure variations in the left ventricle.

\section{In vitro results}

Albune ${ }^{\circledast}$ microspheres diluted 1:200 in 5\% human serum albumin were exposed to overpressures of 160 $\mathrm{mm} \mathrm{Hg}$. Figure 6 shows recordings of the Albunex ${ }^{\circledast}$ microspheres 1 and $5 \mathrm{~s}$ after applying an overpressure of $160 \mathrm{~mm} \mathrm{Hg}$. Figure 6a shows a variety of microspheres sizes; all the microspheres look more or less spherical. Notice that the distance indicator is $10 \mu \mathrm{m}$ and that the bigger microspheres are overrepresented caused by flotation. After $1 \mathrm{~s}$ of overpressure, Fig. 6b shows that some microspheres have disappeared and that the shapes of all the microspheres have changed. This effect is caused by diffusion of the gas inside the microsphere to the surrounding medium. The overpressure is responsible for an undersaturation of the gas concentration in the fluid and therefore a difference in concentration of gas in and outside the microspheres. Figure $6 c$ shows an almost complete disappearance of the microspheres. The remainder of the microspheres are nonspherical and have a decreased gas content. After approximately $20 \mathrm{~s}$, all the microspheres have disappeared.

\section{DISCUSSION}

For a detailed report on safety and efficacy of Albunex ${ }^{\circledR}$ after intravenous injection, we refer to the recent study (Feinstein et al. 1990) in which our center participated.

This study shows that quantitative analysis of the contrast effect at the left side of the heart after an intravenous injection of Albunex ${ }^{\circledR}$ has limitations. These limitations are related to the stability of the microspheres and the filtering action of the lung capillaries.
In the left ventricle, an attenuation of the acoustic power of approximately 2 to $3 \mathrm{~dB} / \mathrm{cm}$ at $3.75 \mathrm{MHz}$ due to the microspheres is noted. De Jong et al. (1992) have shown that this degree of attenuation is apparent for Albunex ${ }^{\circledR}$ when diluted 1:10,000. In the worst case, the $2.5 \mathrm{~mL}$ injectate diluted in the blood volume of the human $(5 \mathrm{~L})$ gives a dilution of $1: 2,000$. Therefore, according to the known relationship between attenuation and concentration, it can be reasoned that the concentration in the left ventricle is much less than expected. This indicates a loss of microspheres between the right ventricle and left ventricle. The difference in backscatter intensities in the left ventricle compared to right ventricle may be explained by three factors: 1) pressure dependency/diffusion of microspheres, 2) filtering action of the lungs, and 3) dilution effect.

The influence of the static ambient pressure on diluted Albunex ${ }^{\circledR}$ is shown in the in vitro study. The in vivo situation deals with a pulsatile system. Cyclic variation in intensities have been reported using sonicated human serum albumin (Shapiro et al. 1990). The videodensity variation during a cardiac cycle in both the ventricle and especially in the left ventricle indicates a large pressure dependency. The effect of sieving action of the lungs can be demonstrated with a simulation of the expected backscatter density.

When Albunex ${ }^{\circledast}$ is intravenously injected, the lung capillaries will sieve the larger microspheres. Figure 7 shows the normalized size distribution of these capillaries (Hogg 1987). It shows that capillaries between 4.5 and $5.5 \mu \mathrm{m}$ are most prevalent. The mean diameter is around $6 \mu \mathrm{m}$. The shaded area in the figure denotes the probability for a particle with a given diameter to pass through these capillaries. For small particles, this probability is equal to 1 , for $6 \mu \mathrm{m}$ about 0.5 and for $10 \mu \mathrm{m}$ about 0.1 .

The effect on the size distribution of Albunex ${ }^{\circledR}$ is shown in Fig. 8. The bar diagram gives the normalized number of counts as function of the channel diameter as measured with a Coulter Multisizer II (De Jong et al. 1992). The Multisizer has an aperture of 50 $\mu \mathrm{m}$ employing 64 channels with diameters ranging from 1 to $35 \mu \mathrm{m}$. The width of each channel increases for larger channel diameters as indicated in the figure. The thick curve in the figure is calculated assuming a filtering given in Fig. 7 to simulate the sieving action of the lung. The larger microspheres disappear while the number of smaller microspheres remains unaffected. The consequences of this effect on backscattering capacity can be calculated for clinically used frequencies based on a model (De Jong and Hoff 1993) describing the acoustic properties of Albunex ${ }^{\otimes}$ micro- 


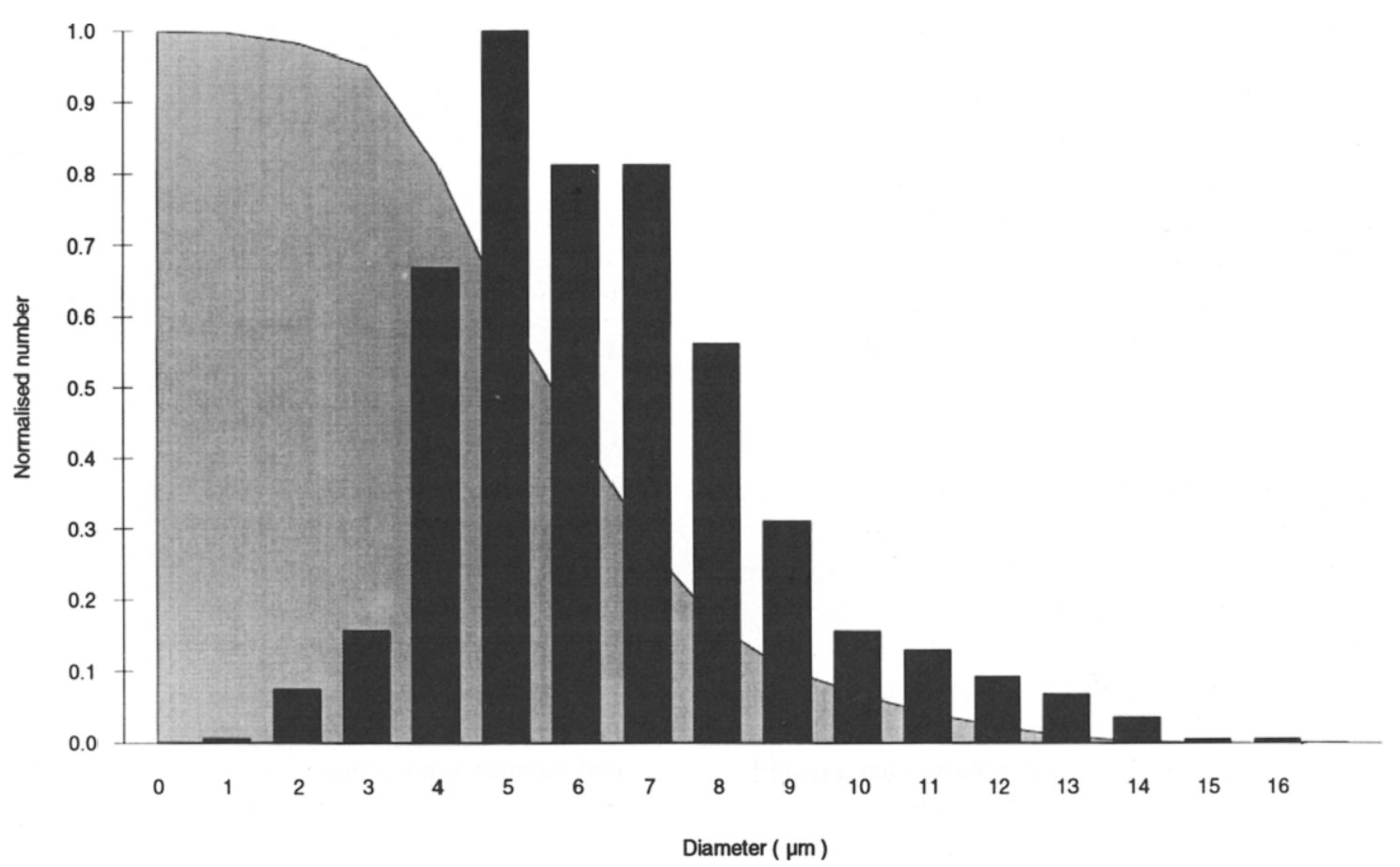

Fig. 7. Normalized size distribution of lung capillaries (Hogg 1987) shown as bars and the probability (shaded area) for a microsphere of a particular size to pass these capillaries.

spheres. For $2.5 \mathrm{MHz}$ the model predicts a $10 \mathrm{~dB}$ difference, while for $5 \mathrm{MHz}$ the calculated difference in backscattered power is $5 \mathrm{~dB}$.
Albunex ${ }^{\circledR}$ is injected undiluted intravenously. When the microspheres arrive in the heart, the solution is diluted and consequently a decrease in the

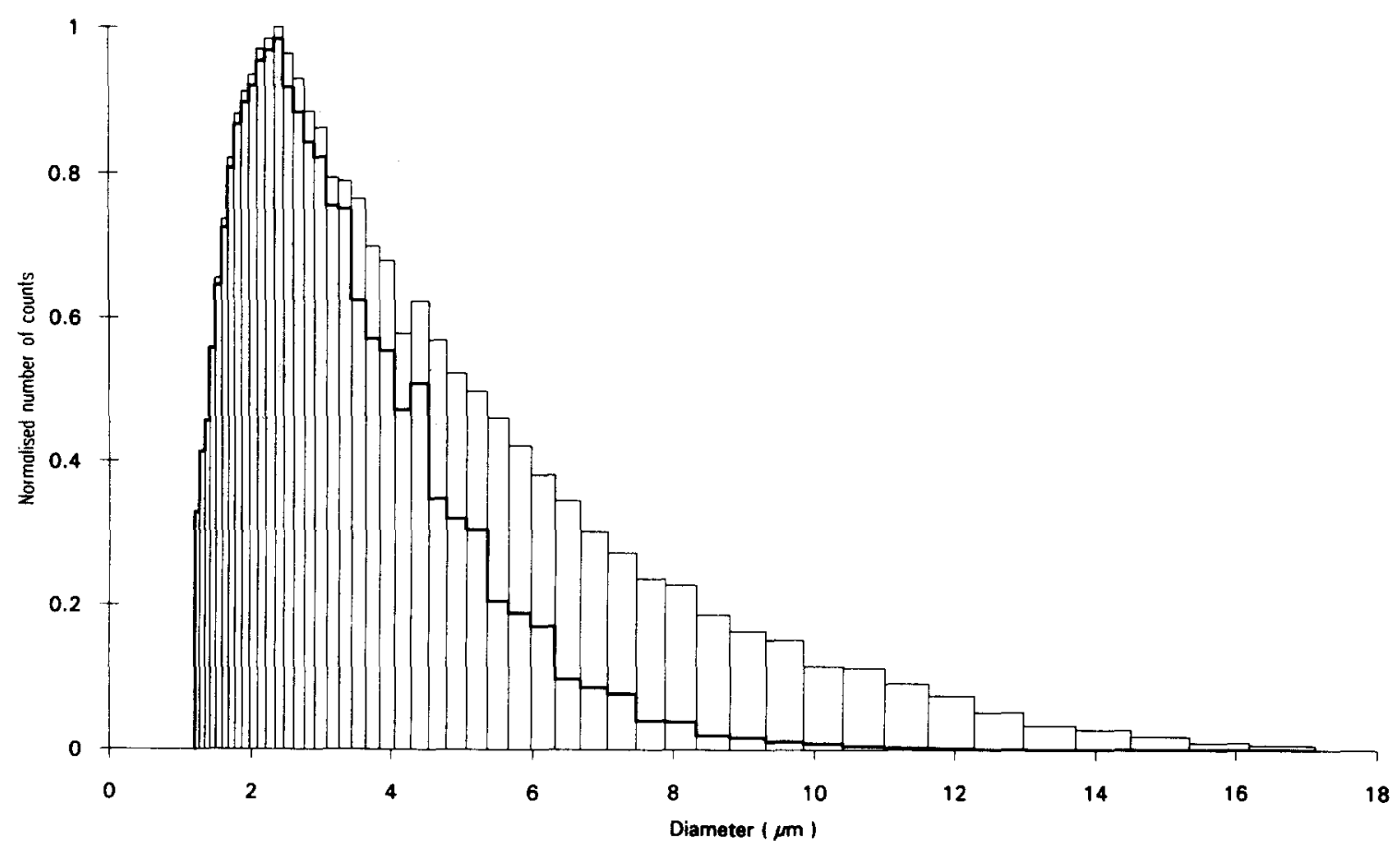

Fig. 8. Normalized size distributions of Albunex ${ }^{\circledR}$ as measured with the coultercounter (De Jong et al. 1992) (thin curve) and calculated size distribution after lung passage assuming the capillary distribution of Fig. 7 (thick curve). 
peak concentration and an increase in contrast duration are measured.

The Albunex ${ }^{\circledast}$ microspheres are filled with air. Venous blood is not saturated for air. Furthermore, the gas content changes when flowing towards the heart, especially when passing the lung circulation. Differences in gas concentrations between the microspheres and the surrounding blood will cause diffusion and consequently will change the microsphere itself.

\section{CONCLUSION}

The study shows that an intravenous injection of Albunex ${ }^{\circledR}$ results in a density increase in the left ventricle in all subjects at the highest dosages used. In general, there is a major difference between the contrast effect in the left ventricle as compared to the right ventricle. This is due to disappearance of microspheres, for which the lung filtration effects and the pressure dependency of the microspheres are considered to be the most important. This explanation is supported by in vitro experiments and computations based on the known properties of Albunex ${ }^{\circledR}$.

Acknowledgements-We greatly acknowledge the technical support of the Clinical Echocardiography Laboratory. We thank Ria Eldering for her secretarial work.

\section{REFERENCES}

Armstrong, W. F.; Mueller, T. M.; Kinney, E. L.; Tickner, E. G.; Dillon, J. C.; Feigenbaum, H. Assessment of myocardial perfusion abnormalities with contrast enhanced two-dimensional echocardiography. Circulation 66:166-173; 1982.

Cheirif, J.; Zoghbi, W. A.; Raizner, A. E.; Minor, S. T.; Winters, W. L.; Klein, M. S.; De Bauche, T. L.; Lewis, J. M.; Roberts, R.; Quinones, M. A. Assessment of myocardial perfusion in humans by contrast echocardiography. I. Evaluation of regional coronary reserve by peak contrast intensity. J. Am. Coll. Cardiol. 11:735-743; 1988

De Jong, N.; Hoff, L.; Skotland, T.; Bom, N. Absorption and scatter of encapsulated gas filled microspheres: Theoretical considerations and some measurements. Ultrasonics 30:95-103; 1992.

De Jong, N.; Hoff, L. Ultrasound scatter properties of Albunex ${ }^{\oplus}$ microspheres. Ultrasonics 31:175-181; 1993.

Feinstein, S. B.; Shah, P. M.; Bing, R. J. Microbubble dynamics visualized in the intact capillary circulation. J. Am. Coll. Cardiol. 4:595-600; 1984.

Feinstein, S. B.; Cheirif, J.; Ten Cate, F. J.; Silverman, P. R.; Hei- denreich, P.; Dick, C.; Desir, R. M.; Armstrong, W. F.; Quinones, M. A.; Shah, P. M. Safety and efficacy of a new transpulmonary ultrasound contrast agent: Initial multicenter clinical results. J. Am. Coll. Cardiol. 16:316-324; 1990.

Gramiak, R.; Shah, P. M. Echocardiography of the aortic root. Invest. Radiol. 3:356-358; 1968.

Hajduczki, K.; Rojagopalan, R. E.; Meerbaum, S.; Drury, J. K.; Corday, E. Effects of intracoronary administered echo contrast agents on epicardial coronary flow, ecg, and global and regional hemodynamics. J. Cardiovasc. Ultrasonogr. 6:84-93; 1987.

Hogg, J. C. Neutrophil kinetics and lung injury. Physiol. Rev. 67:4; 1987.

Kaul, S.; Pandian, N. G.; Okada, R. D.; Pohost, G. M.; Weyman, A. E. Contrast echocardiography in acute myocardial ischemia: I. In vivo determination of total left ventricular "area at risk." J. Am. Coll. Cardiol. 4:1272-1282; 1984.

Keller, M. W.; Feinstein, S. B.; Watson, D. D. Successful left ventricular opacification following a peripheral injection of a sonicated contrast agent: An experimental evaluation. Am. Heart J. 114:570-575; 1987

Keller, M. W.; Glasheen, W.; Smucker, M. L.; Burwell, L. R.; Watson, D. D.; Kaul, S. Myocardial contrast echocardiography in humans II. Assessment of coronary blood flow reserve. J. Am. Coll. Cardiol. 12:925-934; 1988a.

Keller, M. W.; Glasheen, W.; Teja, K.; Gear, A.; Kaul, S. Myocardial contrast echocardiography without significant hemodynamic effect or reactive hyperemia: A major advantage in the imaging of regional myocardial perfusion. J. Am. Coll. Cardiol. 12:39-47; 1988b.

Kloster, F. E.; Friesen, W. G.; Green, G. S.; Swan, H. J. C. Effects of coronary arteriography on myocardial blood flow. Circulation 46:438-444; 1972.

Kondo, S.; Tei, C.; Meerbaum, S.; Corday, E.; Shah, P. M. Hyperaemic response of intracoronary contrast agents during two-dimensional echographic delineation of regional myocardium. $\mathrm{J}$. Am. Coll. Cardiol. 4:149-156; 1984.

Meltzer, R. S.; Serruys, P. W.; McGhie, J.; Roelandt, J. Pulmonary wedge injection yielding left sided echocardiographic contrast. Br. Heart J. 44:390-394; 1980.

Shapiro, J. S.; Reisner, S. A.; Lichtenberg, G. S.; Meltzer, R. S. Intravenous contrast echocardiography with use of sonicated albumin in humans: Systolic disappearance of left ventricular contrast after transpulmonary transmission. J. Am. Coll. Cardiol. 7:1603-1607; 1990.

Tei, C.; Kondo, S.; Meerbaum, S.; Ong, K.; Maurer, G.; Wood, F.; Sakamaki, T.; Shimoura, K.; Corday, E.; Shah, P. M. Correlation of myocardial echo contrast disappearance rate ("washout") and severity of experimental coronary stenosis. J. Am. Coll. Cardiol. 3:39-46; 1984.

Ten Cate, F. J.; Drury, J. K.; Meerbaum, S.; Noordsy, J.; Feinstein S.; Shah, P. M. Myocardial contrast two-dimensional echocardiography: Experimental examination at different coronary flow levels. J. Am. Coll. Cardiol. 3:1214-1226; 1984a.

Ten Cate, F. J.; Feinstein, S.; Zwehl, W.; Meerbaum, S.; Fishbein, S.; Shah, P. M.; Corday, E. Two-dimensional contrast echocardiography. II. Transpulmonary studies. J. Am. Coll. Cardiol. 3:21-27; 1984b. 